\title{
Innovative ideas to sustain in Covid-19 lockdown-A case study
}

\author{
Ravitheja Jampani ${ }^{1 *}$, Vasireddy Yasaswini ${ }^{2}$ \\ ${ }^{1}$ Consultant Orthopaedic Surgeon, ${ }^{2}$ Student of Mechanical Engineering, ${ }^{1}$ Dept. of Orthopaedic Surgeon, ${ }^{1}$ Pace Hospitals, Hyderabad, \\ Telangana, India, ${ }^{2}$ Amrita School of Engineering, Coimbatore, Tamil Nadu, India
}

*Corresponding Author: Ravitheja Jampani

Email: rajtheja@gmail.com

\begin{abstract}
Covid-19 lockdown has made many people of middle- and lower-income class think and reinvent themselves to sustain in this crisis. It was difficult for lower- and middle-income class people to adjust to the situation of lockdown. Government and private institutions have reduced the salaries to the employees in view of 40-day lockdown. Lockdown has made people rethink and reinvent to sustain in this tough time. People have modified their work and style of working to acclimatize to lockdown. Work from home in software industry, telemedicine and video consulting in healthcare industry, online classes and tutoring in education system, farm to house vegetable delivery system in agricultural sector, surge in online pharmacy business, MSME- handmade mask industry, MedTech zones for demand in medical equipment. Private sector isolation centres in partnership with reputed hospitals. We throw light on some of these innovative ideas that could change present and future of living in difficult times.
\end{abstract}

Keywords: Covid-19 crisis, Survival in covid-19, Innovative ideas during covid-19, New jobs during Covid pandemic.

\section{Introduction}

Covid-19 has made man realise the basics of personnel hygiene, personnel health and community health. We are healthy is always a term used in reference with community and not in reference to a family. A healthy community makes a healthy nation. Covid-19 pandemic made lockdown the only option of prevention of transmission in most populated and densely populated country like India. ${ }^{1}$ Preventive measures like lockdown were imposed taking many factors into consideration. The healthcare facilities available in a country, the education and understanding capabilities of its people, the population and density of population in a country, the lifestyle of people, the economic condition of the country. India has many obstacles in each of these factors unpreparedness of healthcare system, understanding capabilities of its people, the economic condition of the country- most of the people depend on daily wages, crowded living spaces and workspaces. All these factors made lockdown the only viable and economic option for a huge and populous country like India. People keep on adapting, thinking and reinventing how to sustain in tough situations.

Some recent innovations in different fields that made a difference in individual and organisations sustainability.

1. Work from home - IT sector and allied fields.

2. Video consulting and tele medicine in healthcare industry.

3. Online teaching in education sector.

4. Medium and small-scale industries in - face mask production.

5. Med tech zones to match demand of medical equipment.

6. Farm to house vegetable delivery system.

7. Isolation centres by hotels in partnership with reputed hospitals.

\section{Work from home - IT Sector}

Information technology, software hubs, IT SEZ'S, huge skyscrapers of offices. Covid-19 lockdown made all these spaces empty. Employees were sent home and asked to work from home on March 3 when first IT employee infected with covid-19 was reported in Hyderabad. Many software employees never encouraged concept of work from home. Hewlett-Packard was in taught that "HP needs all hands-on deck... the more employees we can get into the office the better company we will be". ${ }^{2}$ Yahoo! Says ${ }^{2}$ that "it was banning workers from working at home because 'speed and quality are often sacrificed', choosing instead to highlight the business benefits of "physically being together". Employees have their version of work from home as advantageous because "I often have to work extra time, over and above the formal hours of my job, to get through the work or to help out." However, research and studies later published that Vanderkam highlighted something similar which are the possible benefits of the option of working remotely and how does it impact the way it affects the productivity of employees and quality of their relationship with the coworkers or managers. ${ }^{2-5}$ Even though the concept of work from home was increasing. Covid-19 has made the idea of work from home a boon for both employees and employers. Software employees working in remote location and co ordinating with local managers, team leaders and heads of the company and make sure that the out sourcing client is satisfied with the services, thus the demand and supply chain survives. ${ }^{3,4}$

\section{Video consulting and telemedicine in healthcare system}

Teleconsulting and online consulting are not permitted as per MOHFW India. The basics of diagnosis clinical examination cannot be done through tele medicine or video consultation. Tele medicine is legally not accepted in India. WHO defines telemedicine as The delivery of health care services, where distance is a critical factor, by all healthcare professionals using information and communication technologies for the exchange of valid information for diagnosis, treatment and prevention of disease and injuries, research and evaluation, 
and for the continuing education of healthcare providers, all in the interests of advancing the health of individuals and their communities. ${ }^{6}$

The advantage with virtual and tele consultations..$^{6,7}$

1. Access of best healthcare facilities to distant and poor societies far away from urban health mega structures.

2. Travel and accommodation expenses are saved for the patient.

Disadvantages of telemedicine..$^{6,7}$

1. Diagnosis without clinical examination of patient.

2. The doctor relies on history and most of times doctor and patient language is not the same.

3. Doctor has to rely on lab and radiological report which may or may not be dependable.

4. Is patient and doctor privacy maintained?

5. Legality of doctor's treatment across borders of states, countries, continents?

6. Is there an international law for telemedicine done across borders?

7. Licensing issues- is doctors' degree valid across borders in a different country?

Disadvantages outweigh advantages of telemedicine but, Covid-19 lockdown has made telemedicine and virtual consultation the only viable option for non-emergency medical diseases and disorders. MOHFW has made telemedicine and virtual consultations legal during covid-19 pandemic. ${ }^{8}$ There was increased surge for these services as people are scared to travel and go to hospital fearing transmission of covid-19. Many hospitals started tele and video consultation services during covid-19 pandemic. $^{9-11}$

Why surge of tele and video consultation in covid-19 pandemic?

1. No need to travel to hospital.

2. Economic.

3. Meet and get treated by experts.

4. Mohfw has authorised telemedicine as legal in India during covid-19.

\section{Online pharmacy services}

Along with telemedicine and video consultation online pharmacy services had increased demand during covid-19 pandemic lockdown. Given choice of safe and door delivery of medicines on uploading the prescription on the mobile application people opted for these services in order to avoid exposure.

\section{Advantages ${ }^{12}$}

1. Home delivery of medicines on upload of prescription from a doctor.

2. Selection of drugs that are economical.

\section{Disadvantage $^{12}$}

1. The hygiene and quality of store.

2. The cold chain system and its efficacy in storing medication.

3. Employing cyber doctors to prescribe more medication.
4. Is there any regulatory authority for Verification of prescriptions uploaded by patients?

5. Selling more unregulated drugs.

\section{Online teaching for schools and colleges}

Learning modalities to school and college kids has changed in lot of ways. Methods of teaching ${ }^{13}$

1. Traditional classroom teaching.

2. Online or distance learning.

3. Hybrid method - a combination both the above modalities.

Traditional class room teaching: School kids are mostly accustomed to classroom teaching. Undoubtedly, it's the best way to teach kids. The faculty has an overview of students. It's not only exams and their results which judge the capability and ability of a student but day to day interaction their activity on schools give a better idea about student's overall development. Teachers have a outlook on students in traditional method and help students achieve better in life by supporting the underperforming students.

\section{Advantages ${ }^{13,14}$}

1. Faculty has day to day interaction.

2. Faculty can find underperforming students and take care of them.

3. Social interaction with other kids.

4. A competitive and sportive spirit when mingled among pupils rather than a solitary student.

\section{Disadvantages. ${ }^{13,14}$}

1. Pace of the course must be determined by the instructor.

2. The ability and capability of faculty.

\section{Online learning ${ }^{13-15}$}

Students access classes from a remote location or from home. The classes are streamed either live or recorded and transmitted. Online classes are either recorded videos or live webinars (web+seminar).

\section{Advantages}

1. Classes are flexible as per student's availability.

2. Student can pursue various courses available online and arrange his timetable as per courses.

3. Age is not a limiting factor for online education.

\section{Disadvantages ${ }^{13-15}$}

1. Interaction between students, teacher-student interaction is not present.

2. No one to guide the student.

3. Social interaction and communication skills of student cannot be judged.

4. Students complete many classes over a short period of time. The understand ability of concepts is very superficial.

Hybrid system ${ }^{13,14}$-most of the new age schools follow hybrid system where 70 percent of classes are traditional classroom based and rest of the classes are online based. 
Since a mix of both cultures this is sustainable, flexible and more productive.

Covid- 19 pandemic and lockdown has left no option but only online module of teaching was mode of communication and teaching system available. Most of the schools and colleges completed main course concepts thru online classes. ${ }^{16-18}$ Since this was the only modality of teaching feasible in quarantine, isolation and lockdown times it was mandatory for both students and faculty. There was huge surge not only in teaching school and college kids but most of the healthcare sector sustained during lockdown on information available thru webinars about management of covid-19 pandemic. National and international CME programs were conducted thru webinars ${ }^{19-21}$ (modality of online teaching). (Fig.1, Fig. 2).

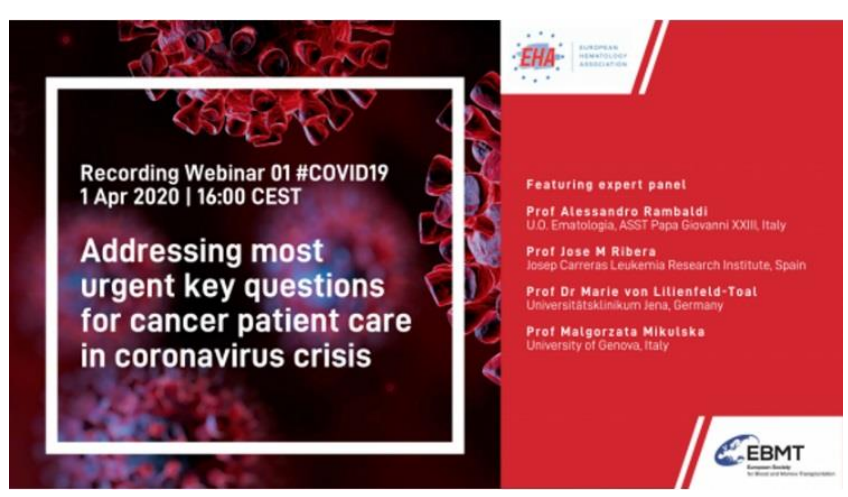

Fig. 1: Webinar on updates about managing Cancer patients during Covid-19 pandemic

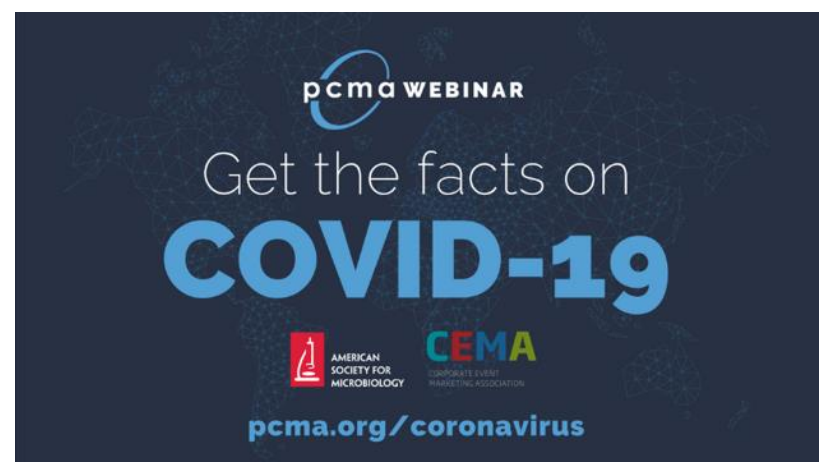

Fig. 2: Webinar on facts about Covid-19.

\section{MSME in face mask production}

Micro, small and medium scale industries (MSME) started production of face masks that could act as barrier in preventing spread of Covid-19 pandemic through droplets. National and international demand of mask production and exporting was on a surge. Government of MSME (ministry of micro, small and medium scale enterprises) has encouraged these enterprises ${ }^{22}$ to start production to meet demands of 130 billion Indian population.

SIDBI (small industries development bank of India) launched safe scheme (SIDBI assistance to facilitate emergency response against corona virus pandemic). The purpose of this scheme is to provide loans to micro, small and medium enterprises to start production of products like face masks, sanitizers and medical equipment to fight against covid-19 pandemic. ${ }^{23}$

MedTech zones were established to produce medical equipment like personnel protective wear and ventilators. ${ }^{24}$

\section{Farm to house fresh vegetables}

The most innovative idea that happened with participation of common man. Most of the auto drivers who were banned from moving during covid-19 lockdown. Most of auto owners have purchased vegetable from agriculture farms and made them available to common people in urban and semi urban population during covid-19 lockdown (Fig. 3, Fig. 4). These auto and small carrier van owners played the role of vegetable markets that are closed during locked down. People of urban and semi urban areas followed social distancing and bought vegetables from these vendors.

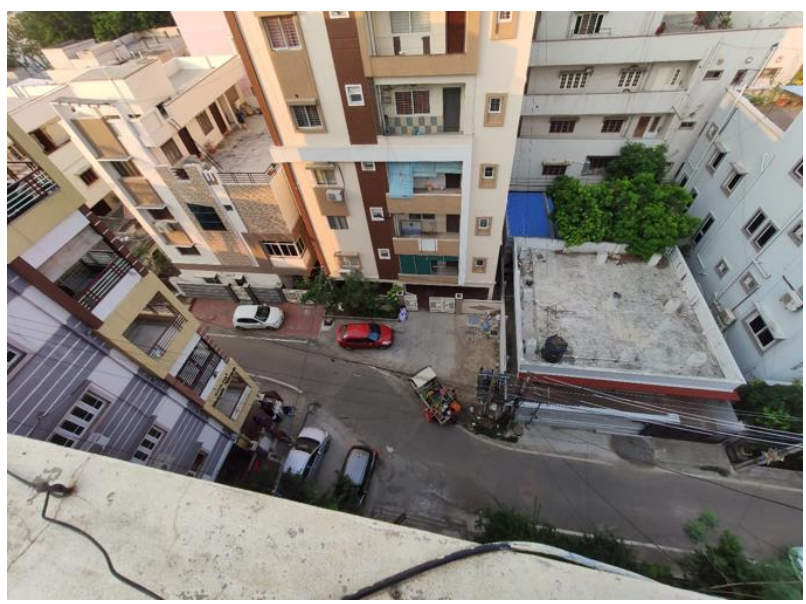

Fig. 3: Trucks carrying vegetables from farm to houses during Lockdown period.

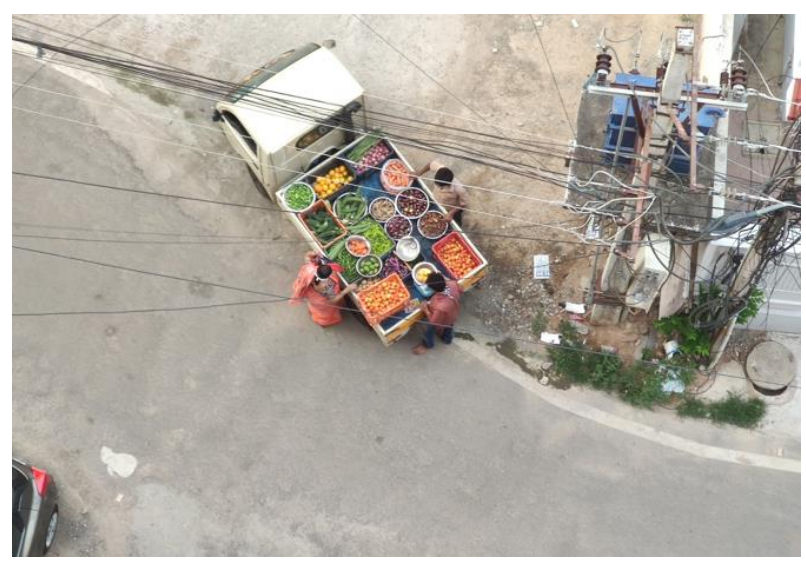

Fig. 4: Social distancing norms being followed at vegetable truck.

Private isolation centres in association with reputed hospitals- Apollo hospitals in association with Lemon tree Hotels, Ginger Hotels, Zomato, Oyo hotels, SBI (state bank of India) launched project KAVACH STAY-I ${ }^{25}$ that provided sanitized and isolated stays to break covid-19 chain (Fig. 4). 


\section{Discussion}

Global economy has crumbled in covid-19 pandemic times. The Indian economy is expected to lose over $\neq 32,000$ crore (US $\$ 4.5$ billion) every day during the first 21-days of lockdown. Up to $53 \%$ of businesses in the country will be affected. Supply chains have been put under stress with the lockdown restrictions in place; initially there was a lack of clarity in streamlining what is an "essential" and what isn't. the informal sectors and daily wage groups are the most at risk. On $27^{\text {th }}$ March the Reserve Bank of India also announced a number of measures which would make available $\neq 374,000$ crore (US\$52 billion) to the country's financial system. On 1 April, World Bank approved \$1 bn in support to India to tackle the coronavirus pandemic. ${ }^{26}$ Amongst such situations there seem to be innovative ideas that worked in favour of common man. Concepts of work from home helped many software employees to have a livelihood. The online teaching system was boon to both students and school faculty. Even though government of India has asked to promote al students to higher classes without exams, it would be foolish on part of schools to promote to higher classes without educating pupils. Thus, online and virtual classes have helped a lot. The health care system which needs to tackle common diseases has been shutdown due to orders from government during the pandemic. The virtual and tele medicine facilities helped common man how to tackle day to day diseases and disorders that can be handled thru online consultation. SIDBI (small industrial development bank of India) launched SAFE, SAFE plus schemes to promote industries that help in tackling Covid-19 medical equipment and other components. Daily wage employees like auto wala have innovated themselves with ideas of farm to house vegetables and made a great deal of help to common people in house to get their food and vegetables delivered to door step. The idea of private isolation wards to tackle lack of beds in hospitals with support from some of the hospitality providers is also a good innovative thought.

\section{Conclusion}

Man and mankind rise to occasion and tackle situations is proved again. These are some of innovative ideas noted during these tough times of Covid-19 pandemic that has helped common man in many ways to deal with problems of daily living.

\section{Source of Funding}

None.

\section{Conflicts of Interest}

None.

\section{References}

1. Jampani R, Nayanatara V. Lockdown- of the people, for the people and by the people. Int J Community Med Public Health. 2020;7:2820-4..

2. Felstead A, Henseke G. Assessing the growth of remote working and its consequences for effort, well-being and work- life balance. New Technology, Work Employment.

2017;32(3):195-212.

3. Ravin S, Myadam Akshay K. Samuel T V. Impact of Working Remotely On Productivity and Professionalism. IOSR-JBM. 2017;19(5):17-9.

4. How to set up work from home quickly and efficiently? [Internet]. Deloitte Croatia. 2020 [cited 15 April 2020]. Available from: https://www2.deloitte.com/hr/en/pages/covid-

19/coronavirus/covid-19-home-office.html.

5. Messenger J, Llave Vargas O, Gschwind L, Böhmer S, Vermeylen G, Wilkens M. Working anytime, anywhere.

6. Telemedicine. Opportunities and developments in member states. Available at www.

who.int/goe/publications/goe_telemedicine_2010.pdf (accessed on 17 Nov 2017).

7. Raposo VL. Telemedicine: The legal framework (or the lack of it) in Europe. GMS Health Technol Assess 2016;12:Doc03.

8. Telemedicine Practice Guidelines [Internet]. 1st ed. new delhi: minstry of health and family welfare; 2020 [cited 18 April 2020]. Available from:

https://www.mohfw.gov.in/pdf/Telemedicine.pdf.

9. Book Appointment or Consult with the Top Doctors Online | Apollo Hospitals [Internet]. Askapollo.com. 2020 [cited 15 April 2020]. Available from:

https://www.askapollo.com/online-doctorsconsultation/renoweddoctor/dr-dattatreyudu-nori.

10. Internet. 2020 [cited 15 April 2020]. Available from: https://www.pacehospital.com/video-consultation.

11. Online Doctor Consultation in Hyderabad | Telemedicine Consultation in Hyderabad [Internet]. Yashoda Hospitals Packages. 2020 [cited 15 April 2020]. Available from: https://www.yashodahospitals.com/packages/product/onlinedoctor-opinion/?utm_source=Google cpc\&utm_medium=cpc\&utm_campaign=Search-OnlineDoctor Consultation\&utm_term=OnlineDoctorConsultation\&gclid $=\mathrm{E}$ AIaIQobChMIq7GaqZnr6.

12. Desai C. Online pharmacies: A boon or bane?. Indian J Pharm. 2016;48(6):615.

13. Tran D. Educational Experiences with Traditional, Online and Hybrid Learning Environments. J Educ Soc Policy. 2016;3(3):60-3.

14. Taylor R. Pros and cons of online learning - a faculty perspective. J Eur Industrial Training. 2002;26(1):4-13.

15. Umford A, Miller A. Online learning in higher education: exploring advantages and disadvantages for engagement. $J$ Comput Higher Educ. 2018;30(3):452-65.

16. Arkorful V, Abaidoo N. The role of e-learning, the advantages and disadvantages of its adoption in Higher Education. Int $J$ Educ Res. 2014;2(12):397-410.

17. Implementation O. Online Learning: Teachers Training and Implementation - Oakridge [Internet]. Oakridge. 2020 [cited 16 April 2020]. Available from: https://www.oakridge.in/specialupdates-bengaluru-mar-20/online-learning-teachers-trainingand-implementation- $2 /$

18. Current Updates [Internet]. Stxaviersdelhi.com. 2020 [cited 16 April 2020]. Available from:

http://www.stxaviersdelhi.com/Notices/FullNotice.aspx?NId=6 83.

19. Entab - CampusCare $® \mid$ School ERP Software [Internet]. Carmel.campuscare.info. 2020 [cited 16 April 2020]. Available from: https://carmel.campuscare.info/.

20. AIIMS C. Information Related to COVID-19 [Internet]. AIIMS NEW. 2020 [cited 13 April 2020]. Available from: https://www.aiims.edu/en/component/content/article/79-aboutaiims/10405-information-related-to-covid-19.html 
21. Webinar - Staff Management during the Covid-19 crisis [Internet]. UITP. 2020 [cited 13 April 2020]. Available from: https://www.uitp.org/events/webinar-staff-managementduring-covid-19-crisis.

22. Webinar: Get the Facts on COVID-19 [Internet]. PCMA. 2020 [cited 13 April 2020]. Available from: https://www.pcma.org/event/webinar-get-the-facts-on-covid$19 /$.

23. Soni S. Covid-19: Govt knocks MSMEs' door to ensure supply of masks, ventilators, other medical equipments [Internet]. The Financial Express. 2020 [cited 16 April 2020]. Available from: https://www.financialexpress.com/industry/sme/msme-eximcovid-19-govt-knocks-msmes-door-to-ensure-supply-ofmasks-ventilators-other-medical-equipments/1917404/.

24. [Internet]. Sidbi.in. 2020 [cited 16 April 2020]. Available from: https://sidbi.in/files/banners/SAFE\%20$\% 200$ ne $\% 20$ pager.pdf.
25. Home -Andhra Pradesh Medtech zone limited (amtz) $\mid$ india's first medical device park [internet]. andhra pradesh medtech zone limited (amtz). 2020 [cited 16 April 2020]. Available from: https://amtz.in/.

26. Home Page [Internet]. Askapollo.com. 2020 [cited 16 April 2020]. Available from: https://www.askapollo.com/stayi/.

27. Economic impact of the 2019-20 coronavirus pandemic in India [Internet]. En.wikipedia.org. 2020 [cited 17 April 2020]. Available from: https://en.wikipedia.org/wiki/Economic_impact_of_the_2019 \%E2\%80\%9320_corona.

28. Jampani R, Chava SP, Dutta SC. COVID-19 lockdown induced fractures. Int J Res Orthop. 2020;6:829-32.

How to cite: Jampani R, Yasaswini V, Innovative ideas to sustain in Covid-19 lockdown-A case study. J Manag Res Anal. 2020;7(2):84-8. 